\title{
Pengembangan Sistem Diseminasi Prakiraan Cuaca Menggunakan Aplikasi Bot Telegram dengan Metode Webhook
}

\author{
Tri Istiana ${ }^{1}$, Raksaka Indra $\mathrm{A}^{2}$, G.S. Budhi Dharmawan ${ }^{3}$, Bowo Prakoso ${ }^{4}$ \\ ${ }^{1234}$ Pusat Jaringan Komunikasi, Kedeputian Instrumentasi Kalibrasi Rekayasa dan Jaringan Komunikasi, \\ BMKG Pusat Jakarta \\ *Corresponding Author, email : tri.istiana@bmkg.go.id
}

\begin{abstract}
Sejak 2016 BMKG memiliki aplikasi mobile berbasis Android dan iOS dengan tajuk @infoBMKG sebagai sarana diseminasi prakiraan cuaca. Sejalan perkembangan pengguna aplikasi instant messaging service maka dirasa perlu untuk melakukan pengembangan sistem dengan model diseminasi informasi dengan metode berbasis permintaan. Fitur Bot Telegram dengan metode Webhook dipilih karena efisien terutama pada developer pembuat Bot dimana membutuhkan sedikit instruksi untuk melakukan pengaturan awal dalam pembuatan Bot Telegram. Adapun penggunaan metode Webhook karena server berada didalam sebuah hosting dan wajib menggunakan https. Sehingga bot telegram akan memberikan respon yang cepat dalam memberikan balasan. Desain ini dimulai dengan pembuatan Bot Telegram (@BMKGbot). Terdapat 3 menu utama yang ditampilkan yaitu, prakiraan cuaca, cuaca bandara dan citra satelit. Respon time yang dihasilkan rata rata $2.54 \mathrm{~s}$ untuk prakiraan cuaca, $2.76 \mathrm{~s}$ cuaca bandara dan $7.28 \mathrm{~s}$ untuk citra satelit. Respon time yang dihasilkan berbeda pada pengujian bot citra satelit karena informasi yang ditampilkan berupa gambar sehingga membutuhkan waktu yang lebih banyak untuk menampilkan informasi tersebut. Direkomendasikan untuk mengimplementasikan @BMKGbot dengan layanan hosting yang andal pada lingkungan operasionalnya untuk mengejar kepuasan pengguna dengan terjaminnya tingkat ketersediaan layanan diseminasi prakiraan cuaca.
\end{abstract}

Keywords: Bot Telegram, Webhook, Respon time

Abstract — An official weather forecast dissemination application named @infoBMKG developed for Android and iOS by BMKG available since 2016. Following users behaviour on instant messaging service application, system development is necessary needed for accommodating request-based dissemination. The Telegram Bot feature with Webhook method is applied because of the efficiency on coding for initial setup in the development of Telegram Bot. Therefore, it allows fast response in sending reply to any request. There are three main menus in the design of the telegram Bot (@BMKGbot) displayed as Weather Forecast, Airport Weather, and Satellite Imagery. As results of performance testing, the average response time dissemination-request 2.54s for Weather Forecast, 2.76s for Airport Weather and 7.28s for Satellite Imagery. Bigger size of data disseminated in an image format of satellite imagery cause longer response time, however the performance testing obtain response times within satisfactory period and meet as expected. It is recommended to implement @BMKGbot at reliable hosting service on its operational environment for chasing users' satisfaction with high availability services in term of weather forecast dissemination.

Keywords: Telegram Bot, Webhook, Respon time

(C) 2020 Elektron Jurnal Ilmiah

\section{PENDAHULUAN}

BMKG merupakan Lembaga Pemerintah Non Departemen (LPND) yang memiliki salah satu tugas dan fungsinya pelayanan data dan informasi di bidang meteorologi. Penajaman mutu serta ekspansi inovatif perlu terus dilakukan BMKG untuk menjadi agensi berkelas dunia di bidangnya. Produk-produk teknologi informasi dan komunikasi telah diluncurkan BMKG guna meningkatkan kualitas serta kuantitas layanan. Tanggal 25 Agustus 2016 BMKG meluncurkan aplikasi mobile@infoBMKG berbasis Android dan iOS.

Kemajuan teknologi komunikasi termasuk meluasnya penggunaan telepon dan telepon pintar memiliki dampak besar dalam mengubah perilaku interaksi sosial. Pengguna aplikasi instant messaging service pun terus bertambah pesat. Fasilitas obrolan pribadi dan group di telepon pintar tidak hanya memfasilitasi komunikasi didalamnya sebuah komunitas, tetapi juga mengubah gaya komunikasi dan koordinasi [7]. Kontributor terbesar untuk penggunaan telepon pintar yang tinggi adalah layanan pesan instan (instant messaging service) dan Voice over IP (VoIP) [1], dengan whatsapp sebagai aplikasi yang paling banyak digunakan [2]. Hampir sama dengan Whatsaap adalah Telegram, ditahun 2020 telah mencapai 400.000.000 pengguna bulanan naik 300 juta setahun yang lalu. Setiap hari setidaknya 1,5 juta pengguna baru mendaftar untuk Telegram. Fitur seperti folder, penyimpanan cloud dan dukungan desktop menjadikan Telegram ideal. Tidak heran Telegram menjadi aplikasi media sosial nomor 1 yang paling banyak diunduh di lebih dari 20 negara[14].Telegram termasuk 8 besar paling popular aplikasi pesan instan di dunia. Satu hal yang menarik tentang Telegram adalah ketersediaan kode sumber klien yang bisa dirakit oleh pengguna. Karena itu, dimungkinkan untuk mengintegrasikan 
aplikasi Telegram dengan sistem informasi dikembangkan secara terpisah. Selain menyediakan kode sumber klien, Telegram juga menyediakan API untuk pengembangan bot, sistem program yang dirancang dengan antarmuka respons kueri sederhana yang dapat diintegrasikan sebagai pengguna. Menggunakan bot, pengguna lain dapat mengirim mempertanyakan pesan untuk mendapatkan tanggapan dari sistem bot terkait [13].

Webhook adalah konsep API yang saat ini semakin populer digunakan. Semakin banyak yang dapat dilakukan di web menjadikan webhook makin banyak digunakan. Webhook atau yang biasa disebut callback adalah cara bagi suatu aplikasi untuk menyediakan aplikasi lain dengan informasi real time. Lebih mudahnya, webhook adalah link URL yang ditambahkan agar data yang dikirim dapat langsung diterima diwaktu sama dengan link URL yang sudah ditentukan[5]. Webhook yang digunakan pada Bot Telegram merupakan fitur yang efisien terutama untuk developer pembuat Bot karena hanya membutuhkan satu instruksi yaitu setWebhook, utnutk melakukan pengaturan awal dalam pembuatan Bot Telegram.

Pada penelitian ini penulis mencoba memberikan suatu alternatif sistem diseminasi prakiraan cuaca untuk melengkapi sistem diseminasi yang sudah ada dengan aplikasi instant messaging service yang banyak digunakan user dan menggunakan metode berbasis permintaan. Sistem diseminasi prakiraan cuaca ini menggunakan aplikasi bot telegram dengan metode Webhook sebagai koneksi ke server telegram dan data XML sebagai penyedia data untuk informasi. Dimana salah satu format data pertukaran dan penyimpanan data secara elektronis adalah menggunakan format data XML[10].

\section{METODE}

\section{A. Perancangan Gambar Teknis Awal}

Rancangan gambar teknis awal terbagi menjadi :

1. Aplikasi menu utama yang terdiri dari menu Prakiraan Cuaca Indonesia, Cuaca Bandara dan Cuaca Satelit

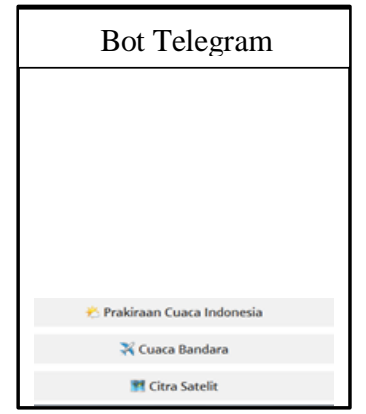

Gambar 1. Rancangan awal aplikasi menu utama

2. Aplikasi menu Prakiraan Cuaca yang terdiri dari menu 34 propinsi dan pembagian wilayah menjadi setiap kota atau kabupaten dengan jumlah keseluruhan 514 kota atau kabupaten.
3. Aplikasi menu Cuaca Bandara yang terdiri dari bandara di Indonesia yang teregister pada kode ICAO (International Civil Aviation Organization)

4. Aplikasi menu Citra Satelit yang terdiri dari citra satelit Indonesia dan citra satelit 34 propinsi

\section{B. Perancangan Topologi Komunikasi Sistem Aplikasi Bot Telegram}

Bot adalah aplikasi pihak ketiga yang berjalan di dalam Aplikasi Telegram [12]. Kombinasi bot telegram dengan berbagai aplikasi yang bermanfaat sebagai asisten messenger untuk pengguna [9].

Topologi komunikasi system aplikasi bot telegram dapat dilihat pada gambar 2 .

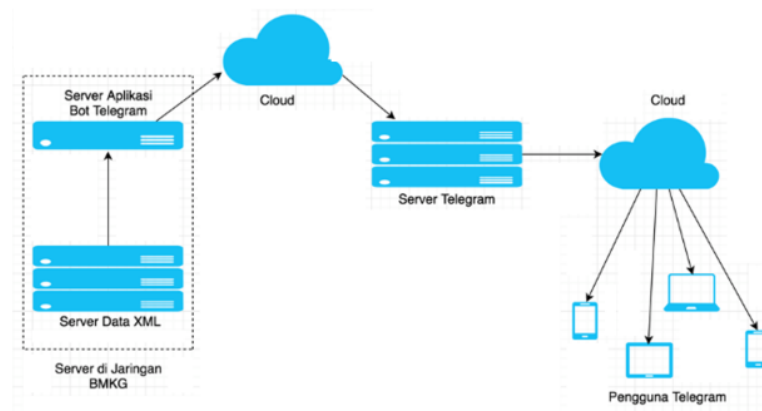

Gambar 2. Topologi Komunikasi Sistem untuk Aplikasi Bot Telegram

Pada topologi komunikasi sistem ini digambarkan posisi dan alur data server dan pengguna. Dimana terdapat 3 bagian utama yaitu server di jaringan BMKG, server Telegram dan pengguna (user). Pada topologi komunikasi sistem untuk aplikasi Telegram ini pada bagian server di jaringan BMKG terdapat 2 server, yaitu server data XML yang berfungsi sebagai penyedia data untuk informasi prakiraan cuaca dengan format XML dan server aplikasi Telegram yang berfungsi sebagai tempat untuk menjalankan sistem aplikasi diseminasi prakiraan cuaca dengan menggunakan Bot Telegram ini.

Bagian selanjutnya adalah server Telegram dimana server Telegram membuka koneksi server mereka untuk para developer Bot Telegram sehingga para developer dapat melakukan komunikasi dengan servernya.

Pada bagian akhir adalah pengguna (user) yang ada di seluruh penjuru dunia. Pengguna ini dapat mengakses Bot Telegram dengan menggunakan aplikasi Telegram yang dapat dipasang (install) dan dijalankan pada smartphone, tablet dan komputer desktop.

Proses pada server di jaringan BMKG secara umum meliputi : 


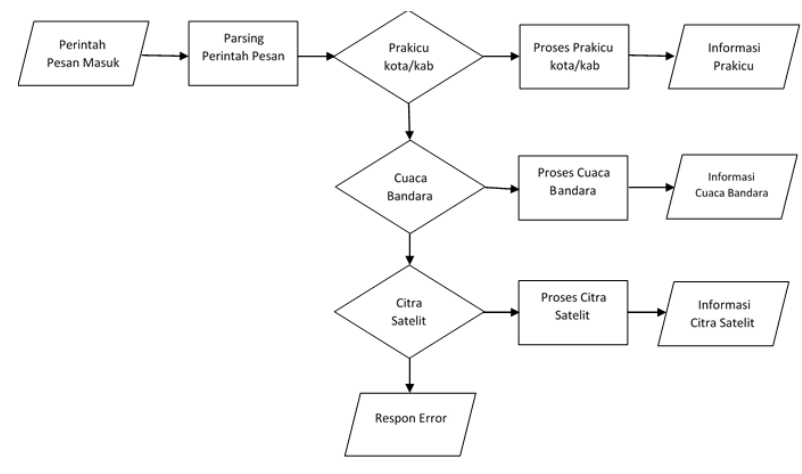

Gambar 3. Proses Pada Server di Jaringan BMKG

Layanan data yang tersedia di penelitian ini mempunyai 2 sifat interaksi, yaitu multi dan satu pesan. Sifat layanan multi pesan merupakan layanan yang memerlukan pesan lanjutan dari pengguna (user) setelah server merespon pesan sebelumnya. Komunikasi akan berlangsung hingga server memiliki informasi yang cukup untuk memberikan respon final. Sifat layanan dengan satu pesan adalah layanan yang hanya memerlukan satu pesan saja untuk mendapatkan respon dari server.

\begin{tabular}{ccccc}
\multicolumn{5}{c}{ Tabel 1. Jenis layanan data yang disediakan } \\
\hline Category & Service & $\begin{array}{c}\text { Initial } \\
\text { Command }\end{array}$ & Interaction & Output \\
\hline \multirow{2}{*}{ Prakiraan Cuaca } & $\begin{array}{c}\text { Propinsi } \\
\text { Kabupaten / } \\
\text { Kota }\end{array}$ & $\begin{array}{c}\text { Prakiraan } \\
\text { Cuaca }\end{array}$ & Multi Message & Test \\
& Provinsi & Multi Message & Test \\
& Info Cuaca & Kabupaten/Kota & Multi Message & Data \\
\hline \multirow{2}{*}{ Cuaca Bandara } & $\begin{array}{c}\text { Nama } \\
\text { Bandara } \\
\text { Info Cuaca } \\
\text { Bandara }\end{array}$ & Nama Bandara & Single Message & Data \\
\hline \multirow{2}{*}{ Citra Satelit } & Indonesia & & & \\
& Propinsi & & Single Message & Citra \\
\hline
\end{tabular}

\section{Registrasi Bot Telegram}

Aplikasi Telegram mempunyai salah satu fitur Bot (RoBot) yang berfungsi untuk melakukan interaksi dengan pengguna secara otomatis tanpa bantuan manusia[3]. Hal ini bertujuan untuk melayani permintaan informasi yang dibutuhkan oleh pengguna Telegram agar menjadi efektif dan efisien.

Bot Telegram adalah bot modern termudah untuk dibandingkan ke bot serupa. Bot Telegram mendukung berbagai bahasa pemrograman, salah satunya adalah PHP. Bot API adalah bot resmi yang disediakan oleh telegram pengembang, yang merupakan entitas terpisah. Fungsi utamanya Bot adalah untuk membantu memberikan informasi[3].

Pembuatan Bot Telegram memerlukan registrasi bot yang dilakukan Botfather account untuk nama bot dan mendapatkan API key. API key digunakan pada setiap request API ke telegram server. Semua command yang diperlukan didaftarkan juga pada BotFather[6][8]

API (Application Programming Interface) adalah sekumpulan perintah, fungsi, dan protokol yang dapat digunakan oleh programmer saat membangun perangkat lunak untuk sistem aplikasi tertentu. API merupakan software yang digunakan untuk dapat berkomunikasi dengan program lainnya seperti akses data, kirim data. API memberikan dua keuntungan utama yaitu : penyederhanaan dan standarisasi. Kedua hal ini dapat dipergunakan sebagai sarana penggunaan API pada sistem yang dibangun[4]. API memungkinkan programmer untuk menggunakan fungsi standar untuk berinteraksi dengan sistem aplikasi yang lain.

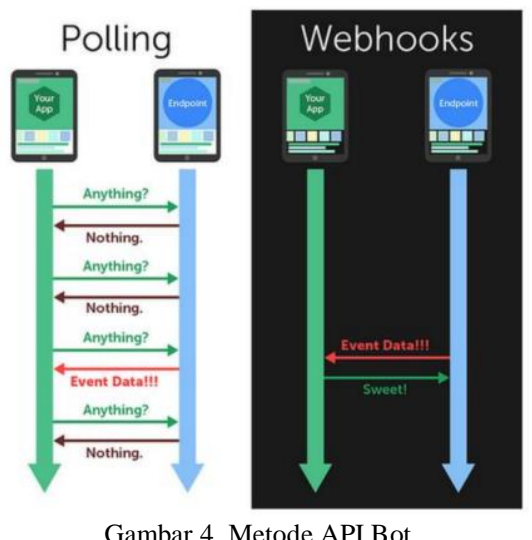

Ada dua metode manajemen bot paling populer, seperti pada Gambar 4, yaitu Polling Panjang dan Webhooks. Fungsi manajemen bot untuk berbagi data secara efisien antara aplikasi dan aplikasi pengguna. Kedua metode memiliki kelebihan dan kekurangan. Polling Panjang adalah metode Telegram default portabel, yang berarti bahwa metode ini dapat berjalan di berbagai perangkat, termasuk komputer, HP, IoT perangkat, dan router. Metode ini tidak diperlukan untuk menggunakan server online. Kelemahannya metode ini termasuk proses membacanya mempunyai waktu yang cukup lama. Proses pembaruan tidak dalam waktu nyata. Webhook memiliki keuntungan dari proses membaca obrolan lebih cepat daripada polling panjang. Metode ini bisa berjalan penuh 24 jam karena dijalankan pada server online yang memiliki sertifikat SSL. Metode ini bisa perbarui skrip secara real time [12].

Dengan menggunakan API Token pada Bot Telegram, maka akan mempermudah programmer untuk berinteraksi dengan Telegram pada sistem aplikasinya[6].

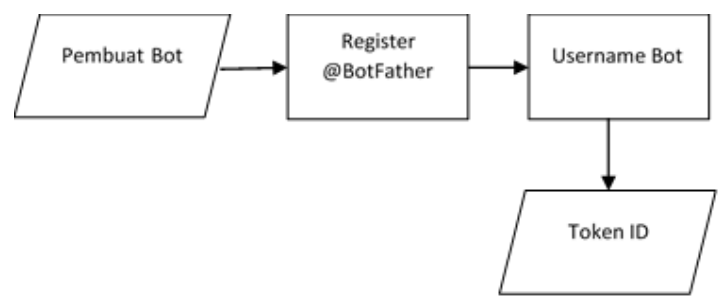

Gambar 5. Proses Register Bot

\section{Konfigurasi Webhook}

Webhook atau yang biasa disebut callback adalah cara bagi suatu aplikasi untuk menyediakan aplikasi lain dengan informasi real-time. Lebih mudahnya, webhook adalah link URL yang ditambahkan agar data 
yang dikirim dapat langsung diterima di waktu sama dengan link URL yang sudah ditentukan. Webhook yang digunakan pada Bot Telegram merupakan fitur yang efisien terutama untuk para developer pembuat Bot karena hanya membutuhkan sedikit 1 instruksi yaitu setWebhook, untuk melakukan pengaturan awal dalam pembuatan Bot Telegram. Perintah ini dapat dijalankan menggunakan perintah cURL atau diketikkan langsung pada URL browser[5]. Server telegram perlu tahu kemana harus mengirimkan pesan. Agar Bot bisa berjalan maka harus melakukan aktivasi Webhook. Perintah untuk mengkonfigurasi Webhook ada dua cara yaitu dengan menggunakan klien APT Telegram yang ada dan menggunakan CURL dari command line sesuai gambar 6 .

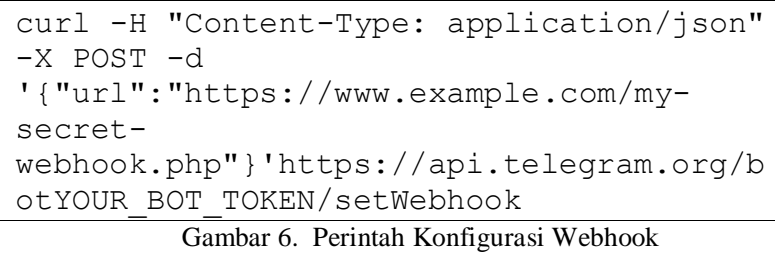

Perintah ini mengirimkan permintaan JSON ke API Telegram dan mengkonfigurasi akun Bot untuk menggunakan my-secret-webhook.php di server. Setelah URL Webhook diatur maka secara otomatis dilakukan konfigurasi.[15]

Metode Webhook sangat baik digunakan jika server berada didalam sebuah hosting dan wajib menggunakan https. Sehingga bot telegram akan memberikan respon yang cepat dalam memberikan balasan.[11]

\section{E. Data $X M L$}

XML (Extensible Markup Language) digunakan dalam banyak aspek pengembangan web dan sering dipakai untuk menyederhanakan penyimpanan dan pertukaran data. Data XML disimpan pada file XML tersendiri. Data yang disimpan pada XML berupa teks, maka data tersebut akan sangat mudah dibaca oleh berbagai aplikasi. Dan data akan tetap valid meskipun dilakukan updgrade terhadap sistem operasi, server, aplikasi baru dan browser baru.

\section{Data XML Prakiraan Cuaca}

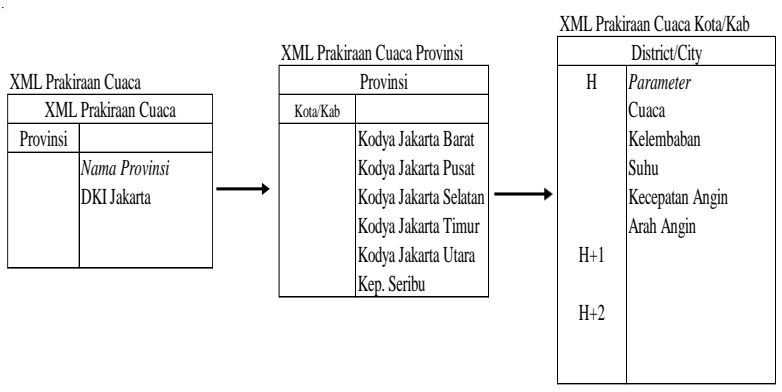

Gambar 7. Proses Data XML Prakiraan Cuaca

\section{Data XML Cuaca Bandara}

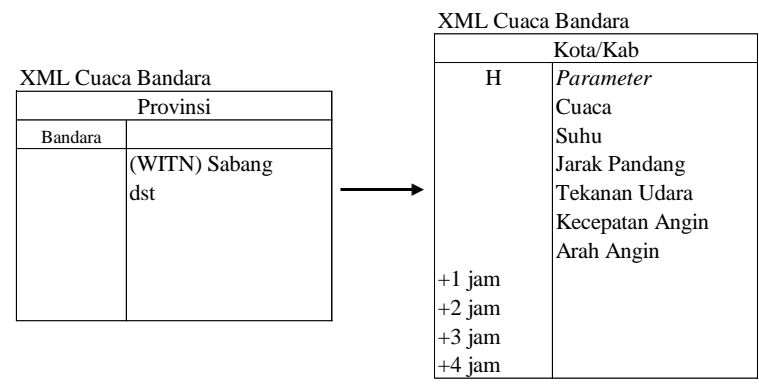

Gambar 8. Proses Data XML Cuaca Bandara

Data XML Citra Satelit

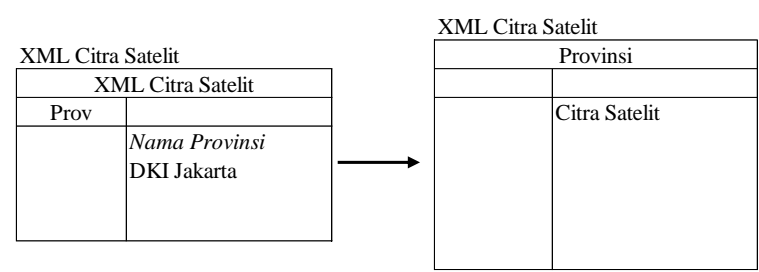

Gambar 9. Proses Data XML Citra Satelit

\section{HASIL DAN PEMBAHASAN}

A. Pembuatan Bot Telegram

Pembuatan Bot melalui aplikasi Telegram adalah dengan mencari akun pembuat Bot dari Telegram yaitu @ BotFather. Kemudian membuat Bot baru, yaitu @ BMKGbot. Selanjutnya memberi identitas pada Bot yang telah dibuat.

Terdapat 4 hal yang perlu diisi untuk memberikan sebuat identitas pada @BMKGbot, yaitu Name, Description, About, dan Profpic (Profile Picture). Pada gambar berikut ditunjukkan pembuatan newbot dan pembuatan identitas dari @BMKGbot yang telah diisi. Maka@BMKGbot sudah siap diakses oleh publik pengguna aplikasi Telegram.

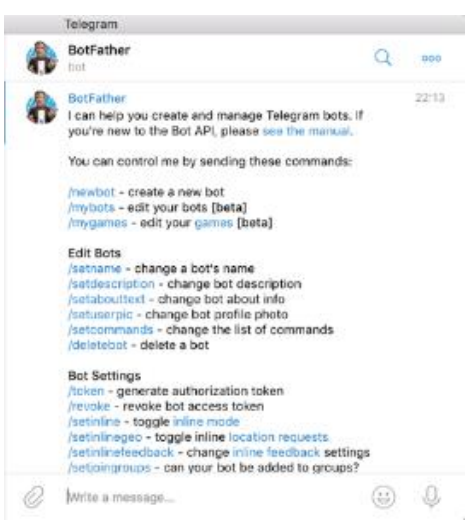

Gambar 10. Halaman dokumentasi pengaturan Telegram Bot yang disediakan oleh Telegram (BotFather) 


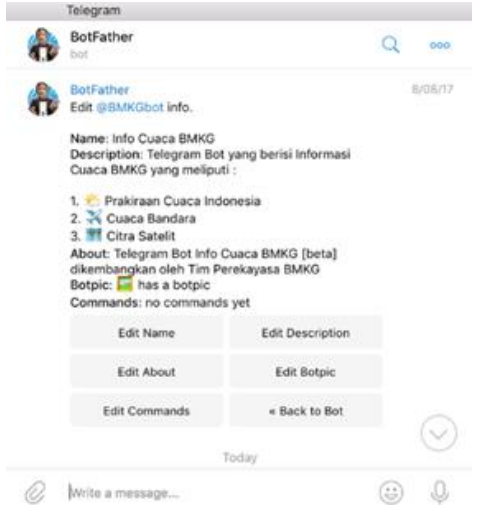

Gambar 11. Registrasi Bot telegram pada BotFather

Bot Telegram yang telah dibuat@BMKGbot mempunyai API Token yang terdiri atas kode unik yang disediakan oleh aplikasi Telegram. Sistem aplikasi untuk Prakiraan Info Cuaca, Cuaca Bandara dan Citra Satelit BMKG dapat terhubung dengan mudah dengan menggunakan API Token yang telah disediakan oleh Telegram.

Setiap Bot Telegram pasti mempunyai API Token yang dapat diambil kapan pun oleh pembuat Bot Telegram. Selain itu API Token tersebut dapat diupdate sesuai keinginan. Untuk mengambil API Token pada @BMKGbot adalah melalui @BotFather kemudian pilih API Token seperti yang ditunjukkan pada gambar 12 berikut.

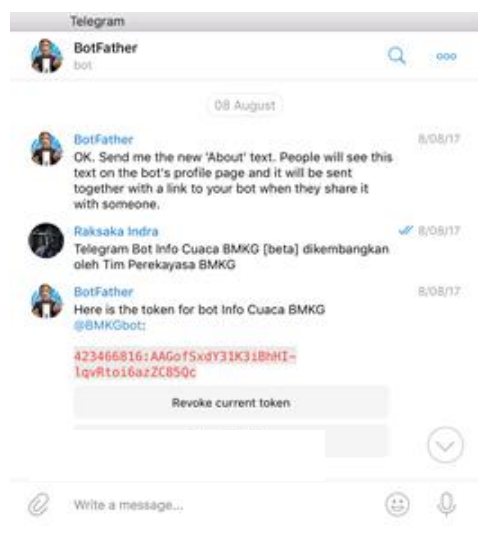

Gambar 12. Tampilan API Token @BMKGbot

Aplikasi bot server dibangun menggunakan bahasa pemrograman PHP dan Data XML. Komunikasi dari server Telegram ke bot server memanfaatkan Webhook dengan protokol https.

\section{B. Konfigurasi Webhook}

Komunikasi dari server Telegram ke bot server memanfaatkan Webhook dengan protokol https. Perintah yang digunakan untuk melakukan konfigurasi Webhook asesuai gambar 13 berikut.

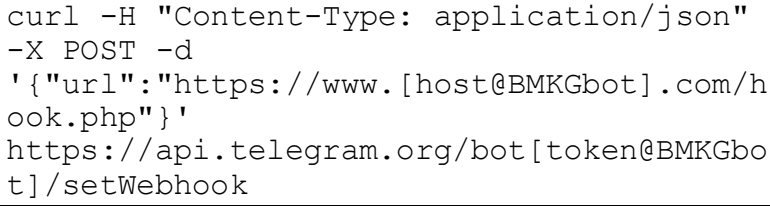

Gambar 13. Perintah Konfigurasi Webhook @BMKGbot

\section{Interaksi Dengan User}

Interaksi yang dilakukan oleh pengguna (user) adalah dengan cara menekan pilihan menu yang telah dipilih pada Bot Telegram. Adapun menu yang tersedia adalah sebagai berikut:

1. Menu Utama menampilkan:

a. Prakiraan Cuaca Indonesia

b. Cuaca Bandara

c. Citra Satelit

2. Menu Prakiraan Cuaca Indonesia menampilkan daftar menu seluruh provinsi di Indonesia. Jika pengguna memilih salah satu dari provinsi tersebut, maka selanjutnya akan menampilkan daftar menu Kabupaten/Kota. Setelah pengguna memilih Kabupaten/Kota, informasi prakiraan cuaca dalam 3 hari akan muncul di Bot Telegram.

3. Menu Cuaca Bandara menampilkan daftar menu nama bandara di Indonesia. Jika pengguna memilih salah satu dari provinsi tersebut, maka informasi cuaca bandara yang berisi cuaca aktual disertai prakiraan cuaca bandara dalam 4 jam ke depan akan muncul di Bot Telegram.

4. Menu Citra Satelit menampilkan daftar menu seluruh provinsi di Indonesia. Jika pengguna memilih salah satu dari provinsi tersebut, maka informasi berupa citra satelit Himawari-8 Enhanhed akan muncul di Bot Telegram.

\section{Data XML}

Data XML Prakiraan Cuaca

Informasi yang ditampilkan adalah meliputi prakiraan cuaca, suhu, kelembaban udara, kecepatan angin, dan arah angin. Informasi tersebut disajikan dalam 3 hari, yaitu hari ini, besok, dan lusa. Setiap satu harinya memiliki 4 waktu, yaitu pagi, siang, malam, dini hari (esok harinya). Informasi prakiraan cuaca tersebut, diambil dari file XML pada masing-masing provinsi sesuai dengan gambar 7 .

Selanjutnya dibuat sebuah fungsi PHP untuk menampilkan informasi kode cuaca untuk hari ini. Untuk menampilkan informasi kode cuaca hari ini tersebut dapat dilihat parameter dengan id="weather" pada XML yang ditunjukkan pada gambar 14.

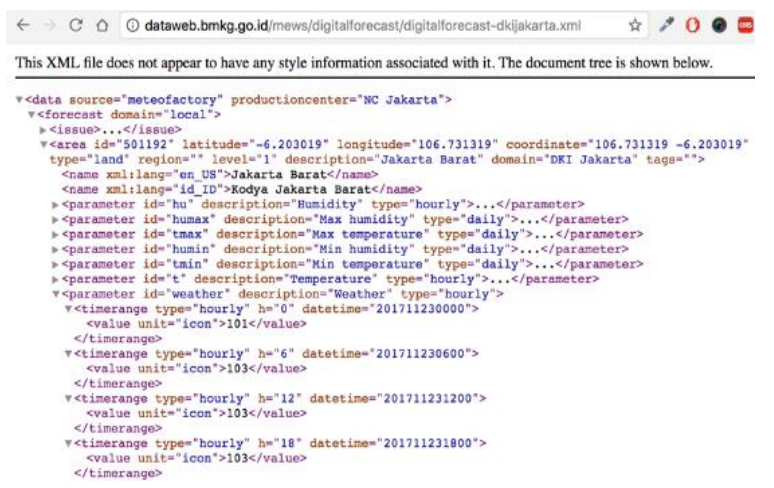

Gambar 14. Struktur data XML untuk parameter cuaca hari ini

Pada pemrograman PHP dibuat fungsi untuk melakukan parsing XML untuk mendapatkan 
informasi kode cuaca hari ini dengan menggunakan variable sesuai gambar 15 .

\$cuaca $=$ \$get $\mathrm{xml}->$ forecast $->$

area [\$row] -> parameter[6]

Gambar 15. Variable kode cuaca hari ini

Di mana \$get_xml adalah file XML pada masingmasing provinsi yang telah ditempatkan di server. Untuk melakukan perulangan digunakan fungsi foreach. \$cuacal yang diisi dengan perintah sesuai gambar 16.

\$cuaca1 = "Cuaca : " .

keterangancuaca (\$cuacaitem1 -> value);

Gambar 16. Perintah perulangan provinsi

Sedangkan untuk menampilkan informasi kode cuaca hari ini pada malam hari digunakan variabel \$cuaca2 yang diisi dengan perintah sesuai gambar 17.

\$cuaca2 = " Cuaca : " .

keterangancuaca (\$cuacaitem2 -> value); Gambar 17. Perintah kode cuaca hari ini

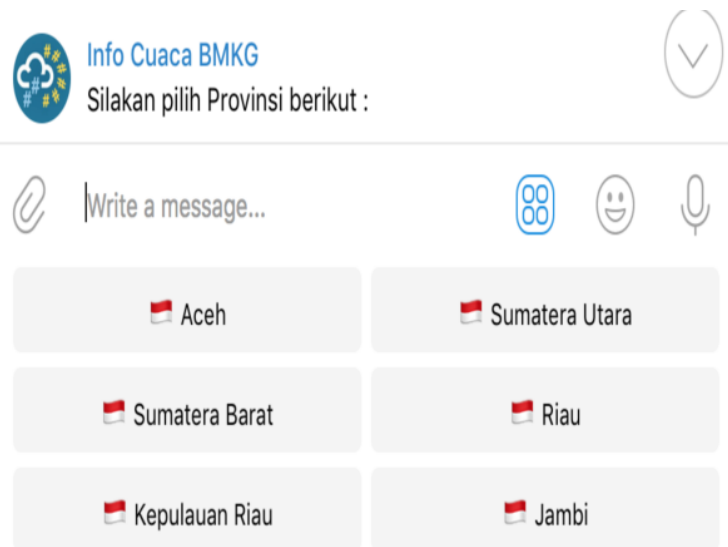

Gambar 18. Tampilan informasi menu prakiraan cuaca pada aplikasi Telegram Bot

Data XML Cuaca Bandara

Cuaca aktual bandara yang akan didesiminasikan di aplikasi Telegram Bot adalah meliputi:

1. Cuaca

2. Suhu dalam Celsius

3. Jarak pandang dalam kilometer $(\mathrm{km})$

4. Tekanan udara dalam hektopascal

5. Kecepatan angin dalam $\mathrm{km} / \mathrm{jam}$

6. Arah angin

Digunakan programming PHP dan library API Telegram Bot untuk menampilkan informasi cuaca aktual bandara yang berasal dari data XML BMKG Aviation.

Untuk memperindah tampilan informasi cuaca aktual bandara, ditambahkan icon pada informasi yang disampaikan. Hasil tampilan informasi cuaca aktual bandara pada Bot Telegram sesuai gambar 19.

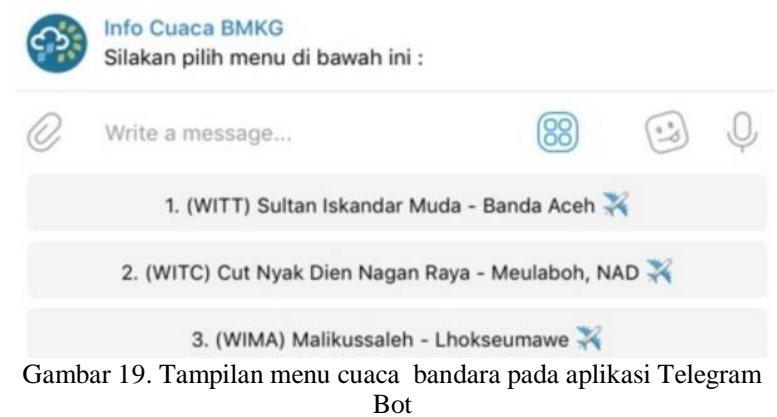

Data XML Citra Satelit

Informasi Citra Satelit diambil dari satelit cuaca Himawai-8 milik JMA Jepang. Pada aplikasi Telegram Bot ini ditampilkan hasil citra satelit cuaca berdasarkan wilayah, yaitu berdasarkan provinsi di Indonesia. Citra satelit cuaca yang ditampilkan berupa gambar dengan ekstensi png. Citra satelit cuaca yang diminta oleh pengguna Telegram Bot diambil dari server Satelit BMKG. Untuk menampilkan informasi citra satelit cuaca Himawari-8 wilayah Indonesia.

Hasil dari permintaan citra satelit cuaca Himawari-8 wilayah Indonesia pada aplikasi Telegram Bot seperti yang ditunjukkan gambar 20. Gambar citra satelit cuaca tersebut dapat diperbesar (zoom-in) oleh pengguna pada perangkat smartphonenya.

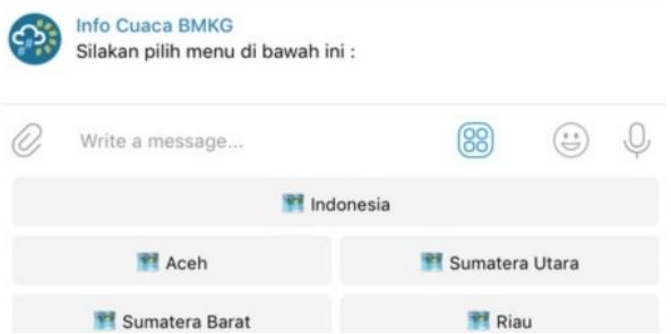

Gambar 20. Tampilan menu citra satelit cuaca wilayah Indonesia pada aplikasi Telegram Bot

\section{E. Hasil Aplikasi}

Hasil pembuatan @BMKGBot dapat dilihat pada tampilan menu utama dari telegram pada gambar 21 .

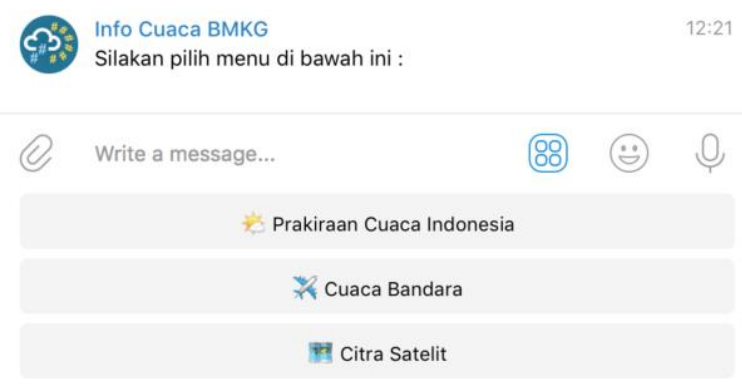

Gambar 21. Tampilan menu utama Info Cuaca BMKG

\section{F. Pengujian}

Pengujian bot telegram yang telah dibuat dilakukan dengan mencoba semua command bot. Pengujian dilakukan pada server khusus testing dengan menggunakan jaringan internet publik dan client 5 perangkat telepon pintar. Setiap command yang 
memiliki sifat interaksi multi message dicoba lebih dari sekali. Rangkuman hasil pengujian bot dapat dilihat pada tabel 2.

Tabel 2. Rangkuman Pengujian Bot (Pada Setiap Perangkat)

\begin{tabular}{c|c|c|c|c|c}
\hline Kategori & $\begin{array}{c}\text { Jumlah } \\
\text { Command }\end{array}$ & $\begin{array}{c}\text { Jumlah } \\
\text { Pengujian }\end{array}$ & $\begin{array}{c}\text { Tingkat } \\
\text { Keberhasilan }\end{array}$ & Respon Time & Rata Rata \\
\hline Prakiraan Cuaca & 576 & 576 & $100 \%$ & $2,16-3 \mathrm{~s}$ & $2,54 \mathrm{~s}$ \\
\hline Cuaca Bandara & 104 & 104 & $100 \%$ & $2,11-3,73 \mathrm{~s}$ & $2,76 \mathrm{~s}$ \\
\hline Citra Satelit & 35 & 35 & $100 \%$ & $6-8 \mathrm{~s}$ & $7,28 \mathrm{~s}$ \\
\hline
\end{tabular}

\section{IV.KESIMPULAN}

Dari hasil penelitian dan perancangan Pengembangan Sistem Diseminasi Prakiraan Cuaca Menggunakan Aplikasi Telegram Bot dengan Metode Webhook ini, terdapat 3 menu Info Cuaca BMKG yang terdiri dari : Prakiraan Cuaca Indonesia, Cuaca Bandara dan Citra Satelit. Dengan total command yang dimiliki adalah 715 command. Output yang diberikan oleh bot dapat berupa teks dan citra (gambar). Tidak menutup kemungkinan ditambahkan command dan informasi BMKG yang diperlukan lainnya. Respon time yang berbeda pada pengujian bot pada citra satelit informasi yang ditampilkan berupa gambar sehingga membutuhkan waktu yang lebih banyak untuk menampilkan informasi tersebut. Direkomendasikan untuk mengimplementasikan @BMKGbot dengan layanan hosting yang andal pada lingkungan operasionalnya untuk mengejar kepuasan pengguna dengan terjaminnya tingkat ketersediaan layanan diseminasi prakiraan cuaca. Penelitian lebih lanjut diperlukan untuk mengembangkan desain sistem yang dioptimalkan guna memperkuat efektivitas kinerja sistem.

\section{REFERENSI}

[1] A. Azfar, K.-K. R Choo and L. Liu, "An Android Communication App Forensic Taxonomy". Journal Forensic Sciciece, 2016, vol. 61, is. 5, pp. 1337-1350, Jul. 2016 [Online]. Availabel: http://dx.doi.org/10.111/15564029.13164

[2] C. Montag, K. Błaszkiewicz, R. Sariyska, B. Lachmann, I. Andone, B. Trendafilov, M. Eibes and A. Markowetz, "Smartphone usage in the 21st century: who is active on WhatsApp?", BMC Resesarch Notes, vol. 8, pp. 1-6, Aug. 2015

https://bmcresnotes.biomedcentral.com/articles/10.1186/s131 04-015-1280-Z

[3] Hasan, 2016 Membuat Sendiri BOT TELEGRAM dari PHP (Lumajang: IDT (Indonesian Digital Teacher) Group)

[4] Maddox, Sarah., 2014, Application Programming Interfaces (APIs) STCSUMMIT 2014. http://summit.stc.org/responsive/summit2014.htm\#!Documen ts/applicationprogramminginterfacesapis.htm.

[5] Nafis, Rifqi Muhammad, 2019, Aplikasi Pemesanan Jasa Tukang Menggunakan Teknologi Webhook dan Google Event Calender, Tesis, Unikom

[6] Notley, Chris, 2016, Telegram: Build a Bot, United States

[7] R. Ling and C.H. Lai, "Microcoordination 2.0: Social Coordination in the Age of Smartphones and Messaging Apps", Journal of Communication, vol. 66, issue 5, pp. 834856, Oct. 2016 [Online]. Available: http://onlinelibrary.wiley.com/wol1/doi /10.1111/jcom.12251/full. [akses 12 Maret 2020]

[8] Sastrawangsa,G., 2017, Pemanfaatan Telegram Bot Untuk Automatisasi Layanan Dan informasi mahasiswa Dalam
Konsep Smart Campus, Konferensi Nasional Sistem \& Informatika

[9] Sajad F, Hossein Heidari T and Azizeh C 2019 TELEGRAM : AN INSTANT MESSAGING APPLICATION TO ASSIST DISTANCE LANGUAGE LEARNING ( App Review ) Teach. English with Technol. 19 132-47

[10] Setiawan, Nugroho, 2005, Sistem Pertukaran Data Antar Basis Data Dengan XML, Program Studi Ilmu Komputer, Unika Soegijapranata, Seminar Nasional Aplikasi Teknologi Informasi 2005 (SNATI 2005) ISBN: 979-756-061-6 Yogyakarta, 18 Juni 2005

[11] Soeroso H., Arfianto, A., Z., Mayangsari, N.,E., Taali, M., 2017 "Penggunaan Bot Telegram Sebagai Announcement System pada Intansi Pendidikan“, Seminar MASTER 2017 PPNS ISSN : 2548-1509 (cetak) | 2548-6527 (online), http://journal.ppns.ac.id

[12] Telegram 2019 Bots: An introduction for developers

[13] T. T. Telegram, "Telegram Bot Platform", 2015 https://telegram.org/blog/bot-revolution

[14] https://telegram.org/blog/400-million

[15] https://www.ntaso.com/lets-make-a-telegram-bot-with-php/ 